Керемов А.Ф. Реакции 5-амино-4-замещенных-6-меркаптопиримидинов с хлорангидридами галогенкарбоновых кислот

УДК 5478533

DOI: $10.21779 / 2542-0321-2020-35-4-104-109$

\title{
А.Ф. Керемов
}

\section{Реакции 5-амино-4-замещенных-6-меркаптопиримидинов с хлорангидридами галогенкарбоновых кислот}

Дагестанский государственный университет; Россия, 367000, 2. Махачкала, ул. М. Гаджиева, 43a; alirzakeremov@mail.ru

Взаимодействием 5-амино-4-этокси и 2,5-диамино-4-метокси-6-меркаптопиримидинов с хлорангидридом хлоруксусной кислоты получены соответствующие 4-замещенные пиримидотиазиноны-6. Реакцией 5-амино-4-метилмеркапто и 5-амино-4-метокси-6-меркаптопиримидинов с хлорангидридом $\beta$-бромпропионовой кислоты получены соответствующие 4-замещенные пиримидо[4,5-в][1,5]-пиримидотиазелиноны-6. Полученные соединения представляют собой твердые бесцветные или окрашенные вещества. Строение синтезированных соединений установлено элементным анализом и ИК-спектроскопией.

Ключевые слова: пиримидотиазиноны, пиримидотиазепиноны, 5-амино-6-меркаптопиримидины, синтез, биологическая активность.

Роль пиримидиновых, пуриновых и подобных структур как ключевых строительных блоков при создании фармацевтических препаратов самого широкого спектра действия чрезвычайно велика. Это относится к антибактериальным и антивирусным, противоопухолевым и нейротропным, противогрибковым, иммунотропным и другим лекарственным препаратам. С целью поиска биологической активности веществ среди би- и трициклических систем 1,4-тиазина и 1,4-тиазепина на основе 5-амино-4-замещенных 6-меркаптопиримидинов и производных 5-формил-6-хлорпиримидина, 1,3-диметил-6-хлорурацила синтезированы соответствующие производные дипиримидотиазепинонов. Полученные соединения обладают способностью тормозить рост перевиваемых опухолей экспериментальных животных [1-4].

С той же целью авторами синтезированы адамансодержащие моно- и полициклические пиримидиновые производные [5], а также серия 5-(арилметилен) гексагидропиримидин-2,4,6-трионов [6].

Рядом авторов разработаны методы получения амино-, алкокси- и алкилсульфанилпроизводных циклопента[4',5'] пиридо[3',2': 4,5]тиено [3,2-d]пиримидинов и пиримидо[5,4': 2,3]тиено-[2,3-с]изохинолинов [7], 1.5-дигидро-2Н-хромено[2,3-d]-пиримидин-2,4(3Н)-дионов из 6-амино-1,3-диметилурацила, среди которых обнаружены соединения, обладающие антибактериальной и противогрибковой активностью [8], 4-аминозамещенных тетрагидропиримидо[4.5-d]азоцинов, содержащих пиримидиновый фрагмент, которые являются высокоактивными ингибиторами ацетил- и бутирилхомен-эстераз in vitro [9], а также новых 8-аминозамещенных пирано [4',,3';4,5]пиридо[3,2:4,5]фуро[3,2-d]пиримидинов [10].

Нами предпринята попытка синтезировать пиримидотиазиноны и пиримидотиазепиноны, используя в качестве исходных соединений 5-амино-4-замещенные-6-меркаптопиримидины и хлорангидриды галогенкарбоновых кислот. 
Керемов А.Ф. Реакции 5-амино-4-замещенных-6-меркаптопиримидинов с хлорангидридами галогенкарбоновых кислот

Первоначально эту реакцию мы исследовали на примере 5-амино-6-меркаптопиримидинов и хлорангидрида хлоруксусной кислоты, чтобы выяснить приемлемость этого метода для получения пиримидотиазинов-6.

Показано, что при взаимодействии 5-амино-6-меркапто-4-этоксипиримидина и 2,5-диамино-4-метил-6-меркаптопиримидина с хлорангидридом хлоруксусной кислоты в безводном ацетоне в присутствии поташа образуется 4-этокси- и 2-амино-4-метилпиримидотиазиноны $(1,2)$.<smiles>[R]c1nc([R])c(N)c(S)n1</smiles><smiles>ClCC(Cl)(Cl)Cl</smiles><smiles>[R]c1nc(C)nc(S)c1NC(=O)CCl</smiles>

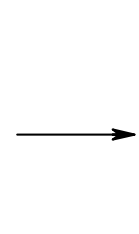

$\mathrm{I} R=\mathrm{H}, \mathrm{R}^{\prime}=\mathrm{OC}_{2} \mathrm{H}_{5}$

II $\mathrm{R}=\mathrm{NH}_{2}, \mathrm{R}^{\prime}=\mathrm{CH}_{3}$<smiles>[R]c1nc([R])c2c(n1)SCC(=O)N2</smiles>

I - II

Первой стадией этой реакции является, вероятно, ацилирование 5-аминогруппы и образование 5-хлорацептиламино-6-меркаптопиримидинов, а затем протекает внутримолекулярное алкилирование меркаптогруппы.

Промежуточное соединение не удалось выделить. Таким образом, было показано, что реакция 5-амино-6-меркаптопиримидинов с хлорангидридами $\alpha$-галогенкислот может быть успешно использована для получения пиримидотиазинонов-6.

Первичным продуктом при взаимодействии 5-амино-4-метокси-6-меркаптопиримидина с хлорангидридом $\beta$-бромпропионовой кислоты является 5- $\beta$-бромпропиониламино-6-меркаптопиримидин (III).

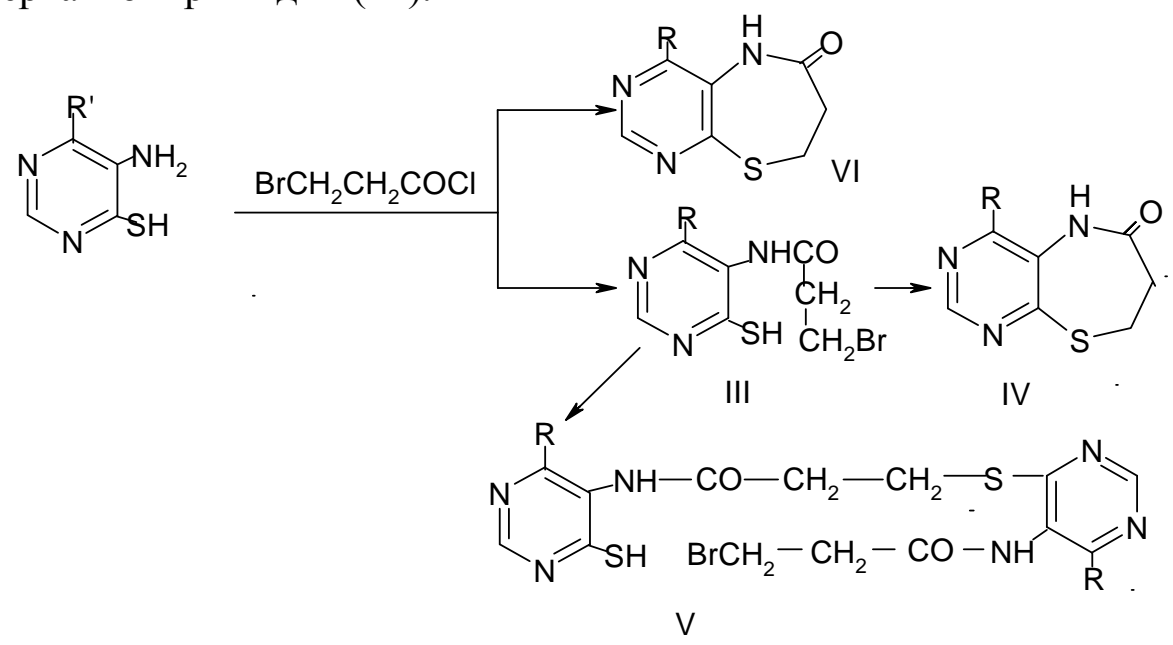

III, IV, V R $=\mathrm{OCH}_{3} \quad \mathrm{VIR}=\mathrm{SCH}_{3}$

Затем в зависимости от применяемых условий может протекать внутримолекулярное или межмолекулярное алкилирование 6-меркаптогруппы, в результате чего образуется пиримидо[4,5-в][1,5]тиазепинон-6 (IV) или дипиримидилсульфид (V). Если соединение (III) не отделить от реакционной среды, а оставить стоять при $18-20{ }^{\circ} \mathrm{C}$ в течение суток, то образуется дипиримидилсульфид (V). Для циклизации соединения (III) в пиримидотиазепинон (IV) его необходимо нагревать в безводном ацетонитриле при 80-90 ${ }^{\circ} \mathrm{C}$. Взаимодействием 5-амино-4-метилтио-6-меркаптопиримидина с хлорангидридом $\beta$-бромпропионовой кислоты получен 4-метилтиопиримидо[4,5-в][1,5]тиазепинон-6 (IV) без выделения промежуточного соединения. 
Керемов А.Ф. Реакции 5-амино-4-замещенных-6-меркаптопиримидинов с хлорангидридами галогенкарбоновых кислот

Таким образом, исследование реакции 5-амино-6-меркаптопиримидинов с хлорангидридом $\beta$-бромпропионовой кислоты привело к разработке удобного и доступного метода получения гетероциклической системы - пиримидо $(4,5-в)(1,5)$ тиазепинонов-6.

Строение полученных соединений подтверждено их аналитическими и спектральными характеристиками. В ИК-спектре соединения III имеются полосы СО и NH-амида (при 3280 и $1672 \mathrm{~cm}^{-1}$ ), а в спектре ПМР - два триплета с химическими сдвигами 3,78 и 3,16 м. д, относящиеся к протонам двух метиловых групп.

В ИК-спектре IV и VI имеются полосы СО и NH-групп амида (1675-1670 и 3230-3090 см ${ }^{-1}$ ), а в ПМР-спектре IV обнаружены сигналы двух $\mathrm{CH}_{2}$ групп, два триплета с центрами при 3,35 и 3,008 м. д. и сигнал группы $\mathrm{OCH}_{3}$ при 4,01 м. д.

Некоторые характеристики синтезированных соединений приведены в табл. 1.

Таблица 1. Характеристика синтезированных соединений

\begin{tabular}{|c|c|c|c|c|c|c|}
\hline $\begin{array}{l}\text { Соеди- } \\
\text { нение }\end{array}$ & $\begin{array}{c}\text { Выход, } \\
\%\end{array}$ & $\mathrm{~T}_{\text {пл. }}{ }^{0} \mathrm{C}$ & \begin{tabular}{|c|} 
Раствори- \\
тель для \\
кристал- \\
лизации
\end{tabular} & $\begin{array}{l}\text { Брутто- } \\
\text { формула }\end{array}$ & Растворитель & $\begin{array}{c}\text { ИК } \\
\text { спектр, } \\
\text { см }^{-1}\end{array}$ \\
\hline I & 60 & 193-194 & $\begin{array}{c}\text { Эта- } \\
\text { нол+вода }\end{array}$ & $\mathrm{C}_{8} \mathrm{H}_{9} \mathrm{~N}_{3} \mathrm{O}_{2} \mathrm{~S}$ & $\begin{array}{c}\text { Р: спирт, хлоро- } \\
\text { форм, бензол, эти- } \\
\text { лацетат. } \\
\text { Н: вода, эфир, пет- } \\
\text { ролейный эфир }\end{array}$ & \begin{tabular}{|c|}
1678 \\
$(\mathrm{C}=\mathrm{O})$ \\
3325 \\
$3200(\mathrm{NH})$
\end{tabular} \\
\hline II & 70 & $>300$ & ДМФ & $\mathrm{C}_{7} \mathrm{H}_{8} \mathrm{~N}_{4} \mathrm{OS}$ & $\begin{array}{l}\text { P: спирт, хлоро- } \\
\text { форм, этилацетат } \\
\text { Н: вода, эфир }\end{array}$ & $\begin{array}{c}1670 \\
(\mathrm{C}=\mathrm{O}) ; \\
3165,3100 \\
(\mathrm{NH}) ; \\
3340,3240 \\
\left(\mathrm{NH}_{3}\right) ;\end{array}$ \\
\hline III & 70 & - & Этанол & $\mathrm{C}_{8} \mathrm{H}_{10} \mathrm{BrN}_{3} \mathrm{OS}$ & $\begin{array}{c}\text { Р: спирт } \\
\text { Н: вода, бензол, } \\
\text { хлороформ, этилаце- } \\
\text { тат, эфир, петролей- } \\
\text { ный эфир }\end{array}$ & \begin{tabular}{|c}
1672 \\
$(\mathrm{C}=\mathrm{O})$ \\
3250 \\
$3220(\mathrm{NH})$
\end{tabular} \\
\hline IV & 70 & $160-162$ & Этан & $\mathrm{C}_{8} \mathrm{H}_{9} \mathrm{~N}_{3} \mathrm{O}_{2} \mathrm{~S}$ & $\begin{array}{c}\text { P: спирт, хлороформ } \\
\text { Н: вода, бензол, эти- } \\
\text { лацетат, эфир, пет- } \\
\text { ролейный эфир }\end{array}$ & \begin{tabular}{|c|}
1670 \\
$(\mathrm{C}=\mathrm{O})$ \\
3230 \\
$3130(\mathrm{NH})$
\end{tabular} \\
\hline V & 37 & 205 & $\begin{array}{c}\text { Эта- } \\
\text { нол+ДМФ }\end{array}$ & $\begin{array}{c}\mathrm{C}_{16} \mathrm{H}_{19} \mathrm{BrN}_{6} \mathrm{O}_{4} \\
\mathrm{~S}\end{array}$ & $\begin{array}{c}\text { Р: бензол } \\
\text { Н: вода, спирт, хло- } \\
\text { роформ, эфир, пет- } \\
\text { ролейный эфир }\end{array}$ & \begin{tabular}{|c|}
1674 \\
$(\mathrm{C}=\mathrm{O})$ \\
3240 \\
$3150(\mathrm{NH})$
\end{tabular} \\
\hline VI & 70 & $199-201$ & Этанол & $\mathrm{C}_{8} \mathrm{H}_{9} \mathrm{~N}_{3} \mathrm{OS}_{2}$ & $\begin{array}{l}\text { P: спирт, хлороформ } \\
\text { Н: вода, бензол, эти- } \\
\text { лацетат, эфир, пет- } \\
\text { ролейный эфир }\end{array}$ & $\begin{array}{c}1675 \\
(\mathrm{C}=\mathrm{O}) \\
3090(\mathrm{NH})\end{array}$ \\
\hline
\end{tabular}


Керемов А.Ф. Реакции 5-амино-4-замещенных-6-меркаптопиримидинов с хлорангидридами галогенкарбоновых кислот

\section{Экспериментальная часть}

4-этоксипиримидо(4,5-b)(1,4)тиазинон-6(I)

Смесь 2г (0,0117 ммоль) 5амино-6-меркапто-4-этоксипиримидина, 1,35 г (0,0119 ммоль) хлорангидрида хлоруксусной кислоты, 1,7 г $\mathrm{K}_{2} \mathrm{CO}_{3}$ в 50 мл безводного ацетона перемывают 12 часов при $18-20{ }^{\circ} \mathrm{C}$. Выделившееся вещество отфильтровывают, промывают водой, сушат, кристаллизуют из водного спирта.

Бесцветные кристаллы.

Выход 1,5 г (60\%),

$\mathrm{T}_{\text {пл. }}=193-194{ }^{\circ} \mathrm{C}$,

ИК-спектр, $\mathrm{v} \mathrm{cм}^{-1}: 1678(\mathrm{C}=\mathrm{O}) ; 3325,3200(\mathrm{NH})$

$\mathrm{C}_{8} \mathrm{H}_{9} \mathrm{~N}_{3} \mathrm{O}_{2} \mathrm{~S}$

Найдено, \%: С 45,19; Н 4,09; N 20,20; S 16,37

Вычислено, \%: С 45,48; Н 4,30; N 19,89; S 15,18

2-амино-4-метилпиримидо (4,5-b)(1,4)тиазинон-6(II)

К смеси 1 г (0,0063 ммоль) 2,5-диамино-4метил-6-меркаптопиримидина в 60 мл безводного ацетона, содержащего 1 г $\mathrm{K}_{2} \mathrm{CO}_{3}$, прибавляют 0,86 г (0,0075 ммоль) хлорангидрида хлоруксусной кислоты. Реакционную массу перемешивают 7 часов при 18-20 ${ }^{0} \mathrm{C}$. Выделившееся вещество отфильтровывают, промывают водой, спиртом, сушат, кристаллизуют из ДМФ.

Белые кристаллы.

Выход 0,85 г $(70 \%), \mathrm{T}_{\text {пл. }} \sim 300^{\circ} \mathrm{C}$.

ИК-спектр, см $^{-1}: 1670(\mathrm{CO}) ; 3165,3100(\mathrm{NH}) ; 3340,3240\left(\mathrm{NH}_{2}\right)$

$\mathrm{C}_{7} \mathrm{H}_{8} \mathrm{~N}_{4} \mathrm{OS}$

Найдено, \%: С 42,45; Н 4,24; N 28,74; S 16,13.

Вычислено, \%: С 42,85; Н 4,08; N 28,56; S 16,32.

4-метокси-5- $\beta$-бромпропиониламино-6-меркаптопиримидин (III).

Смесь 1 г (0,0063 ммоль) 5-амино-4-метокси-6-меркалтопиримидина, 0,9 г (0,0065 ммоль) $\mathrm{K}_{2} \mathrm{CO}_{3}, 1,3$ г (0,0068 ммоль) хлорангидрида $\beta$-бромпропионовой кислоты в 60 мл безводного ацетона перемешивают 2,5 часа при $18-20^{\circ} \mathrm{C}$. Выпавший осадок отфильтровывают и экстрагируют спиртом. Спиртовый и ацетоновый растворы объединяют и упаривают в вакууме досуха. Полученные вещества кристаллизуют из спирта.

Светло-желтые кристаллы, не имеющие определённой $\mathrm{T}_{\text {пл. }}$.

Выход 1,3 г $(70 \%)$.

ИК-спектр, см$^{-1}: 1672$ (CO); 3260, $3220(\mathrm{NH})$.

$\mathrm{C}_{8} \mathrm{H}_{10} \mathrm{BrN}_{3} \mathrm{OS}$

Найдено, \%: С 33,24; Н 3,65; Br 27,03; N 14,68; S 11,10.

Вычислено, \%: С 32,89; Н 3,45; Br 27,35; N 14,38; S 10,98.

4-метоксипиримидо (4,5-в)(1,5)тиазепинон-6 (IV).

Смесь 1 г (0,0063 ммоль) 5-амино-4-метокси-6-меркаптопиримидина, 0,9 г (0,0065 ммоль) $\mathrm{K}_{2} \mathrm{CO}_{3}, 1,3$ г (0,0068 ммоль) хлорангидрида $\beta$-бромпропионовой кислоты в 70 мл безводного ацетона перемешивают 6 часов при $18-20^{\circ} \mathrm{C}$. Выпавший осадок отфильтровывают и экстрагируют горячим ацетонитрилом, раствор упаривают, остаток отфильтровывают и высушивают. Кристаллизуют из спирта.

Бесцветные кристаллы.

Выход 0,9 г $(70 \%), \mathrm{T}_{\text {пл. }} \sim 160-162{ }^{\circ} \mathrm{C}$.

ИК-спектр, см$^{-1}: 1670$ (CO-NH); 3230, $3130(\mathrm{NH})$.

$\mathrm{C}_{8} \mathrm{H}_{9} \mathrm{~N}_{3} \mathrm{O}_{2} \mathrm{~S}$

Найдено, \%: С 45,75; Н 4,21; N 19,95; S 15,02. 
Керемов А.Ф. Реакции 5-амино-4-замещенных-6-меркаптопиримидинов с хлорангидридами галогенкарбоновых кислот

Вычислено, \%: С 45,48; Н 4,29; N 19,89; S 15,18.

4-метокси-5- $\beta$-(4'-метокси-5'- $\beta$-бромпропиониламинопиримидил-6')-меркаптопропиониламино-6-меркаптопиримидин(V).

Смесь 1 г (0,0063 ммоль) 5-амино-4-метокси-6-меркаптопиримидина, 0,9 г $(0,0065$ ммоль $) \mathrm{K}_{2} \mathrm{CO}_{3}$ и 1,3 г (0,0063 ммоль) хлорангидрида $\beta$-бромпропионовой кислоты в 60 мл безводного ацетона перемешивают при $18-20^{\circ} \mathrm{C}$ в течение 2 -х суток. Выделившийся осадок отфильтровывают, экстрагируют спиртом, спиртовой и ацетоновый растворы объединяют и упаривают в вакууме. Кристаллизуют из спирта.

Кремовые кристаллы.

Выход 1,2 г $(37 \%), \mathrm{T}_{\text {пл. }} \sim 205^{\circ} \mathrm{C}$.

ИК-спектр, $v^{-1} \mathrm{~cm}^{-1}: 1674(\mathrm{CO}-\mathrm{NH})$.

$\mathrm{C}_{16} \mathrm{H}_{19} \mathrm{BrN}_{6} \mathrm{O}_{4} \mathrm{~S}_{2}$

Найдено \%: С 39,34; Н 3,70; Br 15,83; N 16,86; S 13,15.

Вычислено, \%: С 38,17; Н 3,80; Br 15,87; N 16,70; S 12,75.

4-метилмеркаптопиримидо $(4,5$ - b) $(1,5)$ тиазепинон-6 ( VI)

Смесь 1 г (0,0057 ммоль) 5-амино-4-метилмеркапто-6-меркаптопиримидина, 1,6 г $\left(0,0116\right.$ ммоль) $\mathrm{K}_{2} \mathrm{CO}_{3}, 1,2$ г (0,0062 ммоль) хлорангидрида $\beta$-бромпропионовой кислоты в 100 мл безводного ацетона перемешивают 8 часов при 18-20 ${ }^{\circ} \mathrm{C}$. Выделившийся осадок отфильтровывают и экстрагируют горячим ацетонитрилом, раствор упаривают, остаток отфильтровывают и высушивают. Кристаллизуют из спирта.

Белые кристаллы.

Выход 0,9 г (70 \%), $\mathrm{T}_{\text {пл. }} \sim 199-201{ }^{\circ} \mathrm{C}$.

ИК спектр, $v_{\text {cм}}{ }^{-1}: 1675$ (CO-NH); $3090(\mathrm{NH})$.

$\mathrm{C}_{8} \mathrm{H}_{9} \mathrm{~N}_{3} \mathrm{OS}_{2}$

Найдено, \%: С 42,10; Н 4,01; N 18,40; S 27,94.

Вычислено, \%: С 42,27; Н 3,99; N 18,48; S 28,21.

\section{Литература}

1. Сафонова Т.С., Немерюк М.П., Лиховидова М.М., Гринева Н.А., Соловьева Н.П., Анисимова О.С., Керемов А.Ф. Синтез, свойства и превращения производных 1,3-диметил-6-(51-аминопиримидилтио-61) урацилов // Химико-фармацевтический журнал. - 2008. - Т. 42, № 1. - С. 13-16.

2. Сафонова Т.С., Немерюк М.П., Гринева Н.А., Лиховидова М.М., Керемов А.Ф. Синтез и свойства производных дипиримидо[4,5-b][5,4-f]1,4-тиазапина // Химикофармацевтический журнал. - 2008. - Т. 42, № 2. - С. 10-13.

3. Safonova T.S., Nemeryuk M.P., Likhovidova M.M., Grineva N.A., Soloveva N.P., Anisimova O.S., Keremov A.F. Synthesis, properties and reactions of derivatives of 1,3dimethyl-6-(-51-aminopyrimidyethio-61)uracies // Pharmaceutical Chemistry Journal. - 2008. - T. 42, № 1. - C. 11-14.

4. Safonova T.S., Nemeryuk M.P., Likhovidova M.M., Grineva N.A., Keremov A.F. Synthesis and properties of dipyrimido[4,5-b][5,4-f]-1,4-thiazepine dezivatives // Pharmaceutical Chemistry Journal. - 2008. -T. 42, № 2. - C. 60-63.

5. Шокова Э.А., Ковалев В.В. Биологическая активность адамансодержащих моно и полициклических пиримидиновых производных. // Химик-фармацевтический журнал. - 2016. -Т. 50, № 2. - С. 3-15.

6. Лужкова С.А., Тырков А.Г., Габитова Н.М., Юртаева Е.А. Синтез и антибактериальная активность 5-(арилметилен) гексагидропиримидин-2,4,6-трионов // Химикофармацевтический журнал. - 2015. - Т.49, № 12. - С. 12-14. 
7. Пароникян Е.Г., Дашян Ш.Ш., Норавян А.С., Минасян Н.С. Синтез производных циклопента [4',5']пиридо[3',2':4,5]тиено[2,3-c][3,2-d]пиримидинов и пиримидо[5' 4':2,3]тиено[2,3-с] изохинолинов // Химия гетероциклических соединений. - 2014. № 8. - C. 1286-1292.

8. Осянин В.А., Осипов Д.В., Павлов С.А., Климочкин Ю.Н. Новый метод синтеза 1,5-дигидро-2Н-хромено [2,3-d] пиримидин-2,4 (3Н)-дионов // Химия гетероциклических соединений. - 2014. - № 8. - С. 1293-1295.

9. Воскресенский Л.Г., Овчаров М.В., Борисова Т.Н., Листратова А.В., Куликова Л.Н., Сорокина Е.А., Громов С.П., Варламов А.В. Синтез 4-аминозамещенных тетрагидропиримидо [4,5-d] азоцинов. // Химия гетероциклических соединений. - 2013. - № 8. C. 267-1274.

10. Сираканян С.Н., Пароникян Е.Г., Гусакян М.С., Норавян А.С. Синтез 8-аминопроизводных конденсированных фуро[3,2-d]-пиримидинов // Химия гетероциклических соединений. - 2010. - № 6. - С. 912-918.

Поступила в редакичию 21 июля 2020 г.

UDC 5478533

DOI: $10.21779 / 2542-0321-2020-35-4-104-109$

\title{
Reactions of 5-amino-4-substituted-6-Mercaptopyrimidines with Halogencarboxylic Acid Chlorides
}

\author{
A.F. Keremov \\ Dagestan State University; Russia, 367000, Makhachkala, M. Gadzhiev st., 43a; alir- \\ zakeremov@mail.ru
}

The reaction of 5-amino-4-ethoxy and 2,5-diamino-4-methoxy-6-mercaptopyrimidines with chloroacetic acid chloride gave the corresponding 4-substituted pyrimidothiazinones- 6 . The reaction of 5-amino-4-methylmercapto and 5-amino-4-methoxy-6-mercaptopyrimidines with $\beta$-bromopropionic acid chloride gave the corresponding 4-substituted pyrimido-1,5pyrimidothiazepinones- 6 . The resulting compounds are colorless or colored solids. The structure of the synthesized compounds was established by elemental analysis and IR spectroscopy.

Keywords: pyrimidothiazinones, pyrimidothiazepinones, $\quad$ 5-amino-6mercaptopyrimidines, synthesis, biological activity.

Received 21 July's 2020 